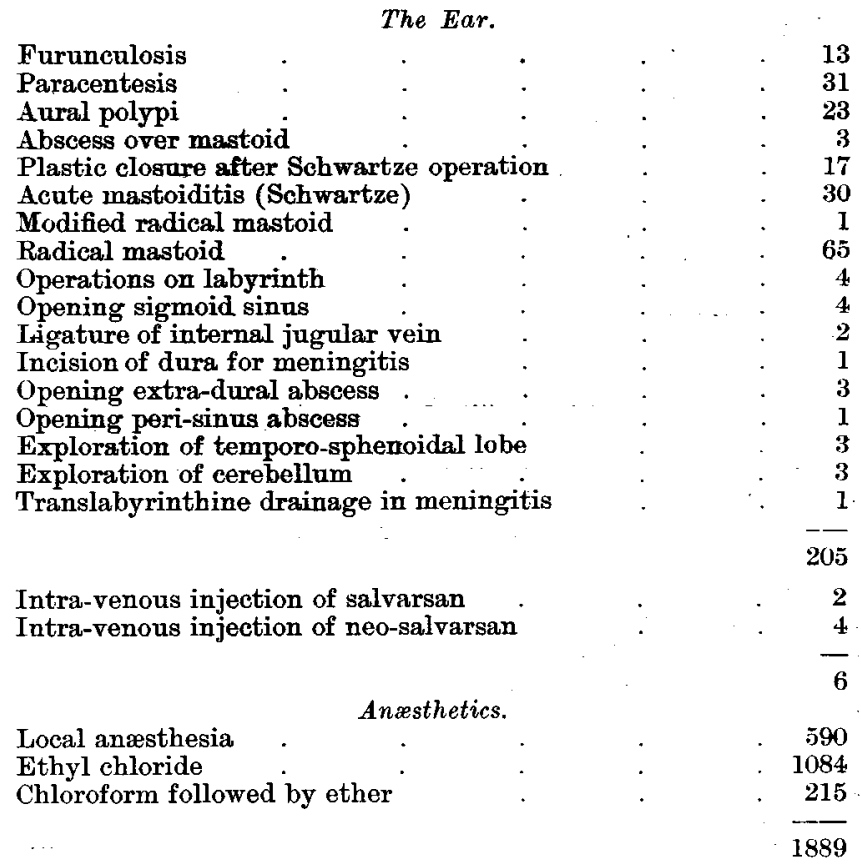

New patients during $1913=3200$.

\title{
ABSCESS OF THE NASAL SEPTUM SECONDARY TO FURUNCLE OF THE YESTIBULE.
}

\section{By Dan McKenzie.}

The patient was a young man, aged twenty-five, a mining engineer in West Africa. He had been home on leave for about three months when I first saw him.

Shortly after leaving West Africa in March, 1913, he became afflicted with boils, one appearing behind the ear and another on the neck. On May 1 he felt some irritation inside the nose on the right side, and two days later the outside of the nose started to swell. There was considerable pain, preventing him from sleeping, and ultimately compelling him to stay in bed. A doctor, who was called in, incised the swelling inside the vestibule, evacuating a quantity of pus which continued to discharge for about a week or ten days. Some yellow "cores" were observed to come away.

Six weeks later, when I first saw him, the discharge from the vestibule had almost ceased, but he was complaining of inability to breathe through the nose, and on examination this was seen to be 
due to a large soft swelling on both sides of the septum, low down and continuous with the swelling in the vestibule. A few days later the vestibular swelling had subsided but there was no change in the septum, so an incision was made into it on the right side and a large quantity of pus was delivered. On putting the little finger into the abscess-cavity in the septum, a fenestra was discovered in the cartilage large enough to let the finger pass through it to the other side.

Recovery ensued rapidly, but with some broadening and depression of the cartilaginous segment of the nasal bridge.

There was no history of accident. 'The most probable explanation of this curious case is that the pus of a vestibular furuncle which had developed around one or more of the hair-follicles in this region had burrowed back in the adherent vestibular subcutaneous and submucous tissue until it reached the smooth subperichondrial space, and that accumulating here, and being prevented from reaching the ethmoidal and vomerine region by the periosteum which encloses the bone edge and shuts it off from the cartilage, it had finally liquefied the cartilage, already damaged by the stripping up of its muco-perichondrium, and so had gained access to the other side of the septum.

It is possible, of course, that there may have been a fenestra in the cartilage prior to this abscess, of the type which has been described and shown by the writer (1), and also by Jefferson Faulder (2), at the Laryngological Section of the Royal Society of Medicine, but that a unilateral septal abscess may find its way to the other side by destroying a portion of the cartilage is undeniable.

The behaviour of septal abscesses as regards burrowing is sometimes peculiar. I can recall a case of traumatic hæmatoma abscess, also shown at the Laryngological Section of the Royal Society of Medicine (3), in which the pus found its way downwards in front of the superior maxilla, protected like the vomer by its periosteum, and opened in the mouth in the gingivo-labial recess of the upper lip to one side of the frænum. It was possible to pass a probe through the fistulous opening in the mouth directly up into the abscess-cavity in the septum.

So far as I have been able to discover there does not seem to be any case described in the literature equivalent to either of these two cases. But as regards the tracking of pus between the nose and the mouth, although the above sequence seems to be unprecedented, on the other hand a number of cases have been recorded in which pus from a carious incisor tooth has burrowed 
its way upwards into the nose and has led to the formation of a subperichondrial septal abscess (4). In some instances the explanation given is that the pus probably reached the septum by way of the anterior palatine foramen, but one or two observers suggest as an alternative route that followed from above by the pus in my case, namely, along the outer aspect of the bone of the maxilla.

Septal abscess is known to follow typhoid fever, smallpox, erysipelas and influenza, but, as I have already said, I have not been able to find any record of its association with furunculosis of the vestibule.

\title{
ReFerences.
}

(1) MoKhnzie, Dan. -Journal of Laryngology, Rhinology, and Otology, vol. $\mathrm{xxy}, \mathrm{p} .632$.

(2) Fadlder, Jefrerson.-Ibid., vol. xxviii, p. 545 .

(3) MoKmnZie, Dan.-Ibid., vol, xxiii, p. 258.

(4) Trautmann, G.-Fränkel's Archiv f. Laryngol., Bd. xxxii, Heft 3, 1910, p. 360.

\section{SOCIETIES' PROCEEDINGS.}

\section{ROYAL SOCIETY OF MEDICINE.-OTOLOGICAL SECTION.}

\author{
January 16, 1914. \\ Mr. Richard Lake, President, in the Chair.
}

\begin{abstract}
Mastoiditis without any Apparent Middle-ear Suppuration. -Dan McKenzie.-A girl, aged six. Tonsils and adenoids were removed on November 27, 1912. For several days after the operation pain was felt at times when the ear was touched, but no genuine earache was experienced. On January 1, 1913, the mastoid region began to show swelling, and on January 2 she returned to hospital, where the cortical mastoid operation was at once performed. As far as could be made out the membrane seemed to have a perfectly normal appearance, and at no time was there any discharge from the meatus. The mastoid cells were occupied by pus and granulations. Recovery was uneventful.

In Mr. Stuart-Low's experience these cases were not uncommon. He had often operated upon children where a mastoiditis has supervened, and even a mastoid abscess, and there had never been any aural discharge nor evident middle-ear implication whatever. Such cases were usually influenzal, and gave a history of "throat first being affected." No doubt in all such instances a fugitive otitis media had been present, but the infection seemed to rapidly pass on and settle in the mastoid antrum, and subsequently set up a mastoiditis, periostitis, and mastoid abscess.

Mr. Whale had under his care at the moment a child, aged five, in whom there was a large peri-sinus abscess in the skull, extending backwards 1 in. along the horizontal part of the sinus. An ounce of pus was
\end{abstract}

